1 Unitat del Son. Servei de Pneumologia, Hospital Clínic, Barcelona, Spain. ${ }^{2}$ CIBER de Enfermedades Respiratorias, Madrid, Spain. ${ }^{3}$ IDIBAPS, Barcelona, Spain. ${ }^{4}$ Facultat de Medicina, Universitat de Barcelona, Barcelona, Spain. ${ }^{5}$ Both authors contributed equally.

\title{
Should the diagnosis and management of OSA move into general practice?
}

\section{Introduction}

Obstructive sleep apnoea (OSA) together with insomnia are the most common sleep disorders [1]. OSA is secondary to complete or partial airway obstruction caused by recurrent pharyngeal collapse during sleep [2], producing loud snoring or choking and frequent awakenings. This chronic sleep disturbance results in daytime sleepiness and fatigue that impedes patient's ability to function, thereby negatively affecting his or her quality of life [3, 4]. In 2015, the American Academy of Sleep Medicine (AASM) task force released quality measures for the care of adult patients with OSA. The first quality measure outcome is to improve detection and categorisation of OSA symptoms and severity [4].

The current prevalence rate of OSA is about 10 to $20 \%$ of middle-aged adults, with at least $4-8 \%$ of men and $2-4 \%$ of women suffering from symptomatic disease [3]. Increased knowledge of OSA by general practitioners and the general population has heightened the demand for consultations with a specialist. Over the past two decades, with the increasing prevalence of obesity, the most important risk factor in sleep breathing disorders, the number of patients diagnosed as suffering from OSA has increased drastically and it will increase over the coming years [3]. However, this increase in demand has not been accompanied by strategic changes in the cost-efficient diagnosis and/or treatment of these diseases. Therefore, there is a pressing need to improve management of this disease by new strategies where definitely primary care medicine has to be involved.

The impact of OSA on global health has been widely reported. It is associated with somnolence and fatigue as mentioned, impaired cognitive function, deficit in sustained attention which may result in an increased motor vehicle accident risk $[5,6]$ and is also a source of lost productivity in the workplace [7]. The Sleep Heart Health and other studies [8] have suggested that patients with OSA are at increased risk of cardiovascular disease, including hypertension [9], myocardial infarction, refractory angina [10], stroke [11] and even death. In addition, nocturnal cardiac arrhythmias [12, 13] and mild-to-moderate pulmonary hypertension can be present in patients with OSA [14]. Metabolic abnormalities, including diabetes are observed in up to $50 \%$ of patients with OSA $[15,16]$. However, it has to be mentioned that causality is not clear in a number
Cite as: Suárez M, Osorio J, Torres M, et al. Should the diagnosis and management of OSA move into general practice? Breathe 2016; 12 : 243-247. 
of the previous mentioned medical entities. In addition, anaesthesiologists have also suggested that patients with OSA have an increased risk of postoperative complications. In a population of surgical patients with OSA, DefLANDre et al. [17] recorded an incidence of $7.17 \%$. Therefore, nowadays OSA represents a major public health issue $[3,4]$.

High prevalence, accessibility and cost problems are the main reasons that justify research into more available and less costly, but comparably reliable, alternatives. To this end, all levels of medical care must be involved: 1) primary care or specialists not directly involved with sleep, 2) second-level hospitals, which should have the ability to perform simplified studies, and 3) tertiary hospitals with complex equipment and multidisciplinary environment have to be prepared to receive patients with complex sleep disorders of breathing as well as to solve the sleep related diseases [18, 19].

\section{Management, screening and assessment for OSA needs to be a priority in primary care settings}

The involvement of different fields or levels of medicine is needed to face the management of OSA patients and search for strategies that guarantee cost-effectiveness [19-22]; specifically focusing on diagnosis, therapeutic decision (i.e. continuous positive airway pressure (CPAP) or other treatments) and follow up. While the follow-up is already implemented in some primary care settings, the diagnosis and therapeutic decision, which are probably the most important, are not yet fully implemented in primary care. Both are handled in sleep centres using different devices and a range of variables, including among the most relevant clinical symptoms (i.e. sleepiness), the potential consequences of OSA (i.e. high risk of cardiovascular events) and the apnoea-hypopnoea index level [22, 23].

It is important to consider two types of questionnaires to be used in primary care. Selfreported questionnaires have already been tested in a primary care environment with predictive performance similar to when implanted in sleep units (Berlin Questionnaire, Stop-Bang Questionnaire, Sleep Apnea Clinical Score) [23]. The other type of questionnaire, including only objective data, may be a better predictor of OSA. Among others (see table 1), the DES-OSA score, a questionnaire developed by DefLANDRE et al. [17] analyses five patient anthropometric variables (Mallampati score, distance between the thyroid and the chin, body mass index, neck circumference and sex) and has been proven to be effective on pre-operative assessments of OSA. Perhaps this type of anthropometric questionnaire, due to its simplicity and objectivity, should be implemented in primary care for screening purposes.

Regarding sleep studies, there are two major types: full polysomnography (PSG) and home respiratory polygraphy (HRP). PSG is considered the diagnostic gold standard. However, access to this procedure is limited because it requires special institutions with trained technicians and is relatively expensive overall. As a result, suspected OSA patients may be left waiting a significant amount of months before being diagnosed and able to initiate medical therapy or CPAP [22]. HRP is a simplified portable monitor that includes sensors to measure airflow, respiratory efforts (assessed by thoracic and abdominal bands), pulse oximetry and body position [24, 25]. Institutions such as the AASM and the American Thoracic Society recommend the management of OSA by HRP in pre-test subjects with high OSA suspicion (usually male patients, snores, with witnessed apnoeas, daytime sleepiness, obese and short neck), without notorious morbidity or suspicion of neurological disorders, as stated in their guidelines for the use of portable monitors [25]. In addition, HRP is considered a cost-effective alternative for OSA diagnosis in selected patients [26, 27].

Randomised controlled studies have already shown that ambulatory management of OSA in specialist sleep unit using HRP and autotitrating CPAP (auto-CPAP) produce comparable patient outcomes with standard laboratory-based sleep study methods [21, 25-28]. However, whether an ambulatory approach would be noninferior when directly and broadly transferred to a primary care setting is still unknown and this represent a major challenge since one-third of primary care patients report symptoms suggestive of OSA [29]. Overnight oximetry should be considered as a screening tool. As demonstrated by the Australian group, an oxygen desaturation index $>16$ in combination with anthropometric objective questionnaires, predicts an apnoea-hypopnoea index $>30$ in most patients [30]. As mentioned, this way of work should be implemented in primary care in the years to come.

\section{Therapeutic decision}

In their study, MASA et al. [26] made a further step by comparing automatic versus manual scoring of home single-channel nasal pressure and showing that automatic scoring is good enough to correctly recommend CPAP in most of the more symptomatic patients. In addition, the authors suggested that the optimal pressure could be calculated automatically by an auto-CPAP device [26]. The existence of these devices for diagnosis and treatment could be very useful in primary care management in the future, along with a networked 


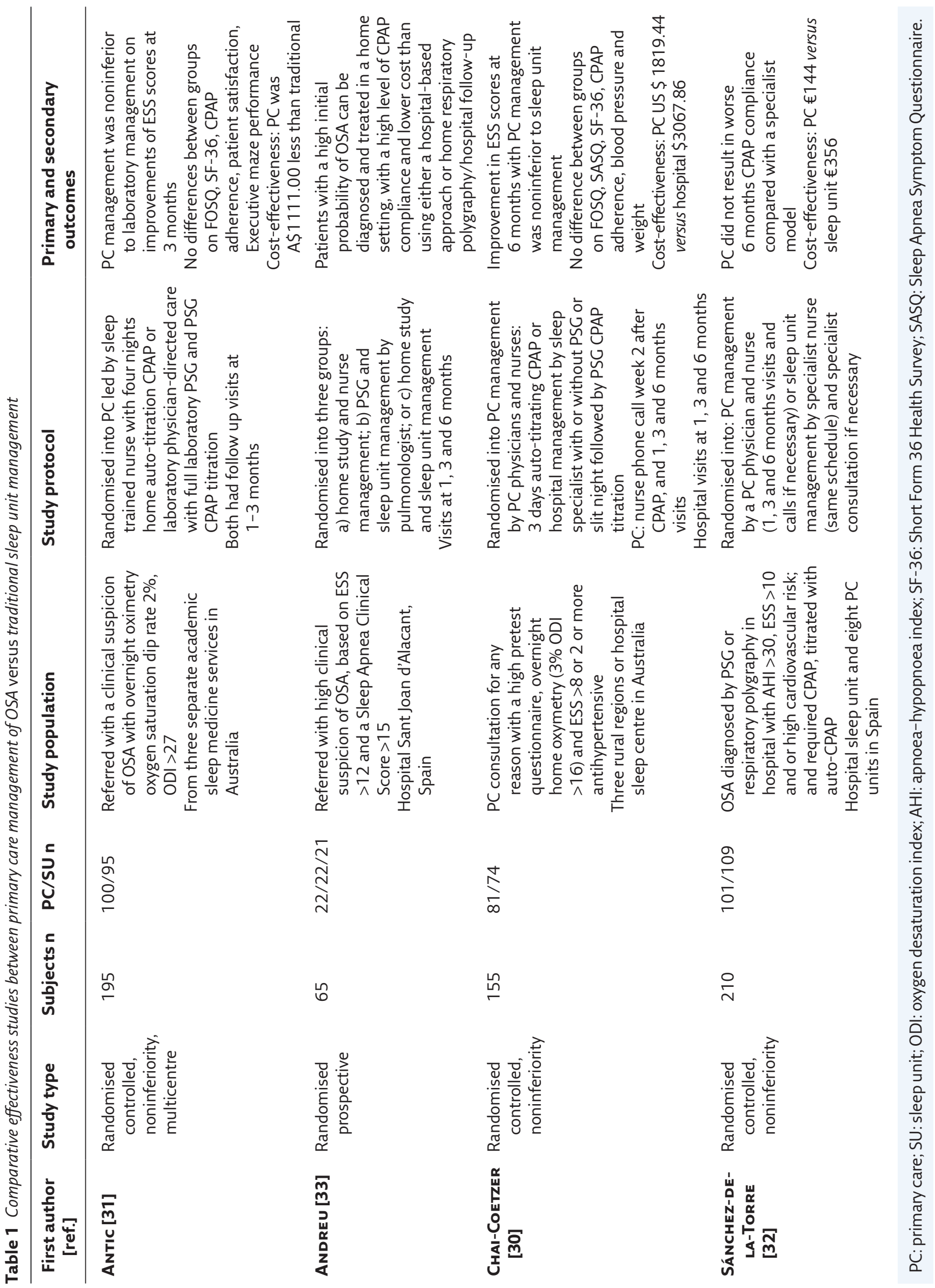


way of working, with educational and training sessions in primary care, which are essential and should be compulsory.

Very few research studies analysed the effectiveness of the management (diagnosis) of high pretest OSA subjects in primary care with appropriate medical backup using simplified devices [30-33] (table 1). These were multicentre, randomised studies performed on an adult population aged over 18 years involving primary care physicians and trained nurses. The main outcomes included were: functional improvements on sleep questionnaires (daytime sleepiness using Epworth Sleeping Scale and Functional Outcomes of Sleep Questionnaire (FOSQ), among others), cognitive impairment tests, CPAP adherence and cost-effectiveness. Although they showed similar functional outcomes and adherence to CPAP treatment in patients managed in a primary care context compared with patients managed with in-laboratory PSG, at present, this way of working has not yet been fully implemented due to several reasons: on the one hand, there is a deficit of time in primary care and, on the other, there is an absence of proper education and training sessions.

It is also worth noting that these trials validating HRP for OSA diagnosis in primary care excluded patients with comorbidities, such as chronic obstructive pulmonary disease and congestive heart failure, for whom, as demonstrated by Olivera et al. [34], the

a)

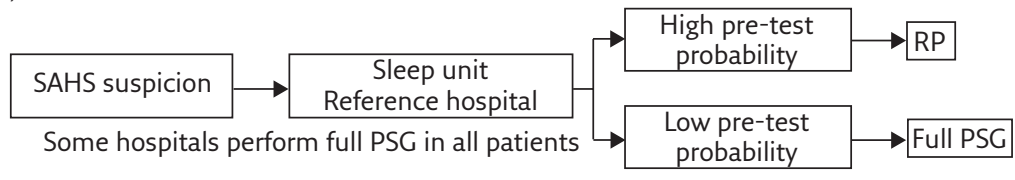

b)

Special patients (known diseases, insomnia, depression, or suspicion of neurological entities)

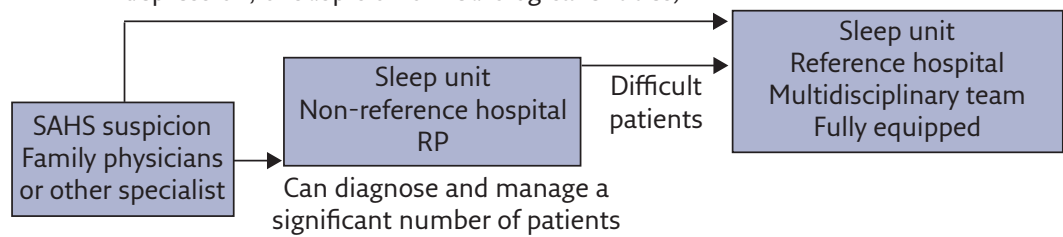

Family physicians or other specialist Simplified devices \#

Sleep unit

Nonreference hospital

SAHS suspicion

Family physicians or other specialist

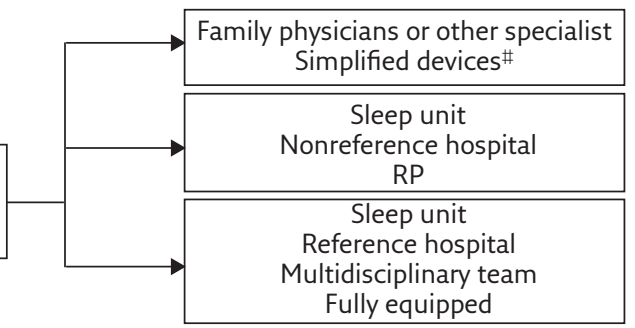

Figure 1 Management of OSA: a) past, b) present and c) future (personalised medicine). SAHS: sleep apnoea-hypopnoea syndrome; RP: respiratory polygraphy. \#: high pre-test patients without comorbidities are eligible for primary care management. Reproduced from [19] with permission from the publisher. concordance between HRP and in-lab PSG (at least with COPD) is inadequate, due either to poor oximetry and/or flow recordings in a significant number of patients.

\section{Final comments}

The management of OSA has evolved over the past 30 years. In the beginning, it seemed that sleep diseases, particularly sleep breathing disorders, were rare and needed to be controlled in laboratory hospital sleep units by a specialist. The use of portable home-based monitoring sleep devices has allowed physicians (especially respiratory sleep specialists) to start diagnosing OSA and prescribing therapy based on home studies. However, to be implemented in a primary care environment, personal use requires proper instruction, and support must be available when needed. At present, family physicians should screen patients based on questionnaires, such as STOP-BANG (snoring, tiredness, observed apnoea, high blood pressure, body mass index, age, neck circumference, gender), that analyse symptoms and anthropometric variables [35] or those that incorporate oximetry [30]. Diagnosis procedures by using simple devices are definitely the next step.

\section{Summary}

When a disease is common, with comorbidities and high costs, all levels of medical care must be implicated. Nurses and family physicians, extra hospital respirologists, non-reference centres, as well as sleep units must work in coordination; each one with duties and rights. Adequate preparation and training in sleep medicine are key.

At present, a significant number of nondifficult OSA patients must be followed by primary medicine (family physicians and specially nurses). Diagnostic procedures are more difficult to perform in primary care but should definitely be the next step in nondifficult patients

We have to realise that, in the future, technology will be better and simpler and a significant number of OSA patients will be managed in primary care. Sleep centres have to be multidisciplinary, working in other crucial fields such as healthy sleep, chronobiology, telemedicine and mechanical ventilation, and should remain in charge of difficult patients such as non-compliers or with important comorbilities.

Finally, it is important that a sleep unit, with adequate preparation and training, should comprise a sleep laboratory; with inside hospital clinic and outside primary care medicine both having a role. 


\section{Conflict of interest}

None declared.

\section{References}

1. Lévy P, Malcolm K, Walter T, et al. Obstructive sleep apnoea syndrome. Nature Rev Dis Primers 2015; 1: 1-19.

2. Dempsey JA, Veasey SC, Morgan BJ, et al. Pathophysiology of sleep apnea. Physiol Rev 2010; 90: 47-112.

3. Mannarino MR, Di Filippo F, Pirro M. Obstructive sleep apnea syndrome. Eur Jf Intern Med 2012; 23: 586-593.

4. Aurora RN, Collop NA, Jacobowitz O, et al. Quality measures for the care of adult patients with obstructive sleep apnea. J Clin Sleep Med 2015; 11: 357-383.

5. Karimi M, Hedner J, Zou D, et al. Attention deficits detected in cognitive tests differentiate between sleep apnea patients with or without a motor vehicle accident. Sleep Med 2015; 16: 528-533.

6. Karimi M, Hedner J, Häbel H, et al. Sleep apnea related risk of motor vehicle accidents is reduced by continuous positive airway pressure: swedish traffic accident registry data. Sleep 2015; 38: 341-349.

7. Mulgrew AT, Ryan CF, Fleetham JA, et al. The impact of obstructive sleep apnea and daytime sleepiness on work limitation. Sleep Med 2007; 9: 42-53.

8. Quan SF, Howard BV, Iber C, et al. The Sleep Heart Health Study: design, rationale, and methods. Sleep 1997; 20 : 1077-1085.

9. Lacedonia D, Carpagnano GE, Sabato R, et al. Characterization of obstructive sleep apnea-hypopnea syndrome (OSA) population by means of cluster analysis. J Sleep Res 2016; in press [DOI: $10.1111 /$ jsr. 12429].

10. Geovanini GR, Pereira AC, Gowdak LHW, et al. Obstructive sleep apnoea is associated with myocardial injury in patients with refractory angina. Heart 2016; 102: 1193-1199.

11. King S, Cuellar N. Obstructive sleep apnea as an independent stroke risk factor: a review of the evidence, stroke prevention guidelines, and implications for neuroscience nursing practice. J Neurosci Nurs 2016; 48: 133-142.

12. Shamsuzzaman AS, Somers VK, Knilans TK, et al. Obstructive sleep apnea in patients with congenital long QT syndrome: implications for increased risk of sudden cardiac death. Sleep 2015; 38: 1113-1119.

13. Wu X, Liu Z, Chang SC, et al. Screening and managing obstructive sleep apnoea in nocturnal heart block patients: an observational study. Respir Res 2016; 17: 16.

14. Imran TF, Ghazipura M, Liu S, et al. Effect of continuous positive airway pressure treatment on pulmonary artery pressure in patients with isolated obstructive sleep apnea: a metaanalysis. Heart Failure Rev 2016; in press [DOI: 10.1007/ s10741-016-9548-5].

15. Hui $\mathrm{P}$, Zhao L, Xie $\mathrm{Y}$, et al. Nocturnal hypoxemia causes hyperglycemia in patients with obstructive sleep apnea and type 2 diabetes mellitus. Am J Med Sci 2016; 351: 160-168.

16. Girardin JL, Zizi F, Clark LT, et al. Obstructive sleep apnea and cardiovascular disease: role of the metabolic syndrome and its components. J Clin Sleep Med 2008; 4: 261-272.

17. Deflandre E, Degey S, Jean-Francois B, et al. Development and validation of a morphologic obstructive sleep apnea prediction score: the DES-OSA score. Anesth Analg 2016; 122: 363-372

18. Montserrat JM. Sleep apnea síndromes. In: Rozman C, Cardellach F, eds. Medicina Interna XVII Edición. Elsevier España, S.L, 2012; pp 748-757.
19. Montserrat JM, Barbé F, Masa F. Diagnostic algorithms. In: Simonds AK, de Backer W, eds. ERS Handbook: Respiratory Sleep Medicine. Sheffield, European Respiratory Society, 2012; pp. 100-106.

20. Cooksey JA, Balachandran JS. Portable monitoring for the diagnosis of obstructive sleep apnea. Chest 2016; 149: 1074-1081.

21. Masa JF, Garcia-Rio F, Ferrer A, et al. Efficacy of home single-channel nasal pressure for recommending continuous positive airway pressure treatment in sleep apnea. Sleep 2015; 38: 13-12.

22. Mansfield DR, Antic NA, McEvoy RD. How to assess, diagnose, refer and treat adult obstructive sleep apnoea: a commentary on the choices. Med J Aust 2013; 199: S21-S26.

23. Miller JN, Berger AM. Screening and assessment for obstructive sleep apnea in primary care. Sleep Med Rev 2015; 29: 41-51.

24. Corral-Peñafiel J, Pepin J-L, Barbe F. Ambulatory monitoring in the diagnosis and management of obstructive sleep apnoea syndrome. Eur Respir Rev 2013; 22: 312-324.

25. Kuna ST, Badr MS, Kimoff RJ, et al. An Official ATS/ AASM/ACCP/ERS Workshop Report: Research Priorities in Ambulatory Management of Adults with Obstructive Sleep Apnea. Proc Am Thorac Soc 2011; 8: 1-16.

26. Masa JF, Corral J, Pereira R, et al. Effectiveness of sequential automatic manual home respiratory polygraphy scoring Eur Respir J 2013; 41: 879-887.

27. Rosen CL, Auckley D, Benca R, et al. A multisite randomized trial of portable sleep studies and positive airway pressure autotitration versus laboratory-based polysomnography for the diagnosis and treatment of obstructive sleep apnea: the HomePAP study. Sleep 2012; 35: 757-767.

28. Mulgrew AT, Fox N, Ayas NT, et al. Diagnosis and initial management of obstructive sleep apnea without polysomnography: a randomized validation study. Ann Intern Med 2007; 146: 157-166

29. Chai-Coetzer CL, Antic NA, Rowland LS, et al. A simplified model of screening questionnaire and home monitoring for obstructive sleep apnoea in primary care. Thorax 2011; 66: $213 e 219$.

30. Chai-Coetzer CL, Antic NA, Rowland LS, et al. Primary care versus specialist sleep center management of obstructive sleep apnea and daytime sleepiness and quality of life. a randomized trial. JAMA 2013; 309: 997-1004.

31. Antic NA, Buchan C, Esterman A, et al. A randomized controlled trial of nurse-led care for symptomatic moderatesevere obstructive sleep apnea. Am J Respir Crit Care Med 2009; 179: 501-508.

32. Sánchez-de-la-Torre M, Nadal N, Cortijo A, et al. Role of primary care in the follow-up of patients with obstructive sleep apnoea undergoing CPAP treatment: a randomised controlled trial. Thorax 2015; 70: 346-352.

33. Andreu AL, Chiner E, Sancho-Chust JN, et al. Effect of an ambulatory diagnostic and treatment programme in patients with sleep apnoea. Eur Respir J 2012; 39: 305-312.

34. Oliveira MG, Nery LE, Santos-Silva R, et al. Is portable monitoring accurate in the diagnosis of obstructive sleep apnea syndrome in chronic pulmonary obstructive disease? Sleep Med 2012; 13: 1033-1038.

35. Nagappa M, Liao P, Wong J, et al. Validation of the STOPBang questionnaire as a screening tool for obstructive sleep apnea among different populations: a systematic review and meta-analysis. PLoS One 2015; 10: e0143697. 